\title{
Impact of including hemp concrete hysteresis on its hygrothermal behavior modelling at wall and room scales
}

\author{
Georges Costantine $^{1}$, Chadi Maalouf ${ }^{1}$, Tala Moussa ${ }^{1,2}$, Elias Kinab ${ }^{3}$, Guillaume Polidori ${ }^{1}$ \\ ${ }^{1}$ Research Group of Engineer Sciences GRESPI, SFR Condorcet FR CNRS 3417, University of \\ Reims-Champagne-Ardenne, 51 687, Reims, France \\ ${ }^{2}$ International University of Beirut, Department of Mechanical Engineering, Beirut, Lebanon \\ ${ }^{3}$ Lebanese University, Faculty of Engineering II, 1204 Roumieh, Lebanon
}

\begin{abstract}
Hemp concrete is a bio-composite material known by its ability to regulate external temperature and relative humidity variations making it an interesting insulator. Several researches conducted on wall scale show that including hysteresis phenomenon could improve hemp concrete hygrothermal behavior prediction in the modelling. On the contrary, others prove that reliable results could be obtained using average sorption curve instead. Moreover, the study of this impact on room scale is very scarce.

This work aims to evaluate the impact of including the hysteresis occurring between hemp concrete sorption curves in the modelling at two different scales. At wall scale, the hygrothermal behavior of hemp concrete walls subjected to real weather conditions is studied. At room scale, the study focuses on the room indoor conditions and energy consumption with or without using hysteresis. Preliminary results show a high impact of hysteresis on temperature and relative humidity evolutions within the wall. Although, this impact is less perceived at room scale.
\end{abstract}

\section{Introduction}

Relative humidity is an important factor regarding building performance evaluation. Energy consumption, occupants health and comfort (Wolkoff, 2018), air quality (Simonson et al., 2002) and envelopes durability (Viitanen et al., 2010) are affected by indoor relative humidity levels. Therefore, seeking accurate building performance assessment requires a reliable determination of relative humidity variational behaviour. For this purpose, considerable efforts have been developed to predict hygrothermal behavior of building materials through involving HAM predictive models (Rode and Woloszyn, 2007).

In parallel, vegetal fiber materials have undergone notable evolution in construction field thanks to their interesting thermal and hydric properties and ability to absorb air carbon dioxide (D'Alessandro et al., 2014), namely hemp concrete (Moussa et al., 2018). Plentiful researches, devoted on hemp concrete material, have been conducted on wall scale (Amziane and Arnaud, 2013), (Colinart et al., 2013),(Maalouf et al., 2014). They succeeded to validate its hygrothermal behavior when subjected to different climatic conditions.
However, controversial suggestions are found in this area regarding hemp concrete hysteresis in numerical modelling. In fact, while Fabbri and McGregor (2017) show that promising numerical results are obtained without hysteresis implementation, Van Belleghem et al (2010), Y. Ait Ouméziane (2013), and Lelievre et al., (2014) prove high hysteresis impact on hygrothermal behavior prediction improvements. Moreover, these phenomena are rarely studied in literature at room and building scales (Costantine et al., 2018) (Moujalled et al., 2018).

In light of these findings, this work aims to apprehend hemp concrete hygrothermal behavior at wall scale by developing a numerical model studying hemp concrete hysteresis. The results are compared to experimental data provided by Lelievre et al. (2014) and to ones delivered by a basic heat and transfer model based on average sorption curve. After that, hemp concrete hygrothermal behavior on room scale is studied. The impact of hysteresis on indoor virtual office conditions are evaluated, in addition to energy consumption required for heating and cooling.

\section{Hysteresis modelling}

Modeling of hemp concrete sorption isotherms is based on Carsten Rode empirical approach (Rode Pedersen, 2005) that figured in Hansen (1986) work. The model proposed is very suitable for hygroscopic materials like wood. Sorption curve general equation is given by:

$$
\frac{\mathrm{u}}{\mathrm{u}_{\mathrm{s}}}=\left(1-\frac{\ln \varphi}{\mathrm{A}}\right)^{-\frac{1}{\mathrm{n}}}
$$

Where $\mathrm{u}$ is the water content $\left(\mathrm{kg}^{\mathrm{kg}} \mathrm{kg}^{-1}\right)$ for a fixed temperature, $\mathrm{u}_{\mathrm{s}}$ the maximum water content at saturation (kg. $\mathrm{kg}^{-1}$ ), and A, n two calibrations constants. Mass water content $\mathrm{u}$ and volumetric water content $\theta\left(\mathrm{m}^{3} \cdot \mathrm{m}^{-3}\right)$ are linked together by:

$$
\theta=\mathrm{u} \times \frac{\rho_{0}}{\rho_{\mathrm{l}}}
$$

$\rho_{0}$ and $\rho_{\mathrm{l}}$ representing dry material and water density respectively. Consequently, sorption curves can be represented through: 


$$
\frac{\theta}{\theta_{\mathrm{s}}}=\left(1-\frac{\ln \varphi}{\mathrm{A}}\right)^{-\frac{1}{\mathrm{n}}}
$$

Hysteresis is observed between sorption curves of hygroscopic building materials, such as hemp concrete. Water is not ejected from materials pores at the same manner it fulfils them. Effectively, contact angles between water and pores are higher in adsorption than in desorption (Leon and Uantachrome, 1998). Other studies provide a general interpretation of hysteresis based on interactions occurring in interconnected spaces between pores (Naono and Hakuman, 1993).

Several models describing hysteresis phenomenon are presented in literature (Mualem, 1974) (Kool and Parker, 1987). Pedersen (1990) empirical is chosen in this study. It is based on material hydric capacity weighted values, or slopes of adsorption and desorption curves defined as follows (Carmeliet et al., 2005):

$$
\begin{gathered}
\xi_{\mathrm{a}}=\frac{\partial \mathrm{u}_{\mathrm{a}}}{\partial \varphi} \\
\xi_{\mathrm{d}}=\frac{\partial \mathrm{u}_{\mathrm{d}}}{\partial \varphi}
\end{gathered}
$$

Where a and $\mathrm{d}$ represent respectively adsorption and desorption, $\varphi$ relative humidity in $\%$. With this approach and taking into account equation (6), scanning curves slopes between adsorption and desorption are calculated from the main sorption isotherms as described below, $\gamma_{a}$ and $\gamma_{\mathrm{d}}$ being two calibration constants:

$$
\begin{aligned}
& \xi_{\text {hys }, \mathrm{a}}=\frac{\gamma_{\mathrm{a}}\left(\theta-\theta_{\mathrm{a}}\right)^{2} \xi_{\mathrm{d}}+\left(\theta-\theta_{\mathrm{d}}\right)^{2} \xi_{\mathrm{a}}}{\left(\theta_{\mathrm{d}}-\theta_{\mathrm{a}}\right)^{2}} \\
& \xi_{\text {hys,d }}=\frac{\left(\theta-\theta_{\mathrm{a}}\right)^{2} \xi_{\mathrm{d}}+\gamma_{\mathrm{d}}\left(\theta-\theta_{\mathrm{d}}\right)^{2} \xi_{\mathrm{a}}}{\left(\theta_{\mathrm{d}}-\theta_{\mathrm{a}}\right)^{2}}
\end{aligned}
$$

Hysteresis modeling is not limited to implement atomic classes related to adsorption, desorption and intermediate sorption curves equations, but to take into account material hydric history and to identify transitions from adsorption cycles to desorption ones. Consequently, an appropriate algorithm is applied at each time step comparing water content with previous time steps.

\section{Mathematical approach}

\section{Sorption curves fitting}

Adsorption, desorption and mean sorption curves are fitted based on experimental measurements of (Lelievre et al., 2014). Hemp concrete properties are listed in Table 1 below (Lelievre et al., 2014). Considering Rode approach, $\theta \mathrm{s}, \mathrm{A}$, and $\mathrm{n}$ coefficients are calculated by least squares method on adsorption, desorption and mean sorption curves. Figure 1 shows sorption isotherms fitting according to the Rode approach.

Table 1: Hemp concrete properties

\begin{tabular}{|c|c|}
\hline Properties & Hemp concrete \\
\hline $\begin{array}{c}\text { Density } \\
\left(\mathbf{k g}^{-\mathbf{3}}\right)\end{array}$ & 450 \\
\hline $\begin{array}{c}\text { Heat capacity } \\
\left(\mathbf{J . k g}^{-\mathbf{1}} \mathbf{K}^{\mathbf{- 1}}\right)\end{array}$ & 1000 \\
\hline $\begin{array}{c}\text { Thermal } \\
\text { conductivity } \\
\left(\mathbf{W} . \mathbf{m}^{-\mathbf{1}} \mathbf{K}^{\mathbf{- 1}}\right)\end{array}$ & $\begin{array}{c}\lambda=0.00818+ \\
2.76 \times 10^{-4} \mathrm{~T}+ \\
0.0024 \mathrm{~W}\end{array}$ \\
\hline $\begin{array}{c}\text { Emissivity } \\
(-)\end{array}$ & 0.8 \\
\hline $\begin{array}{c}\text { Coefficient of } \\
\text { vapor resistance } \\
(-)\end{array}$ & 5 \\
\hline
\end{tabular}

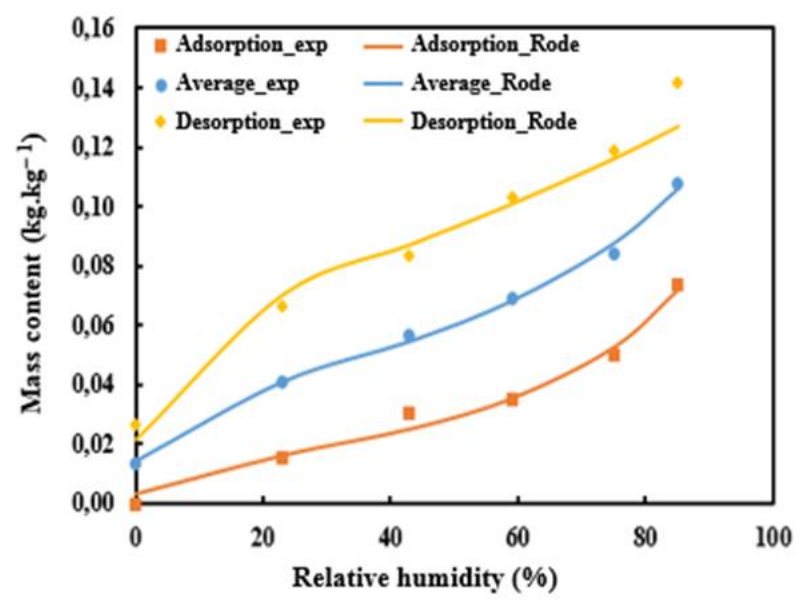

Figure 1: Sorption curves fitting using Rode's approach.

\section{Hysteresis model calibration}

As appeared in equations (6) and (7), hysteresis model requires a calibration through calculation of two constants $\gamma_{\mathrm{a}}$ and $\gamma_{\mathrm{d}}$. For this purpose, and using NordTest protocol (Lelievre, 2015) and same properties of Table 1, mass variations of hemp concrete specimens are investigated. Comparison between experimental mass measurements provided by (Lelievre, 2015) and numerical mass calculation given by hysteresis model permits to deduce that $\gamma_{\mathrm{a}}=0.85$ and $\gamma_{\mathrm{d}}=0.97$ are suitable for hysteresis calibration (Figure 2).

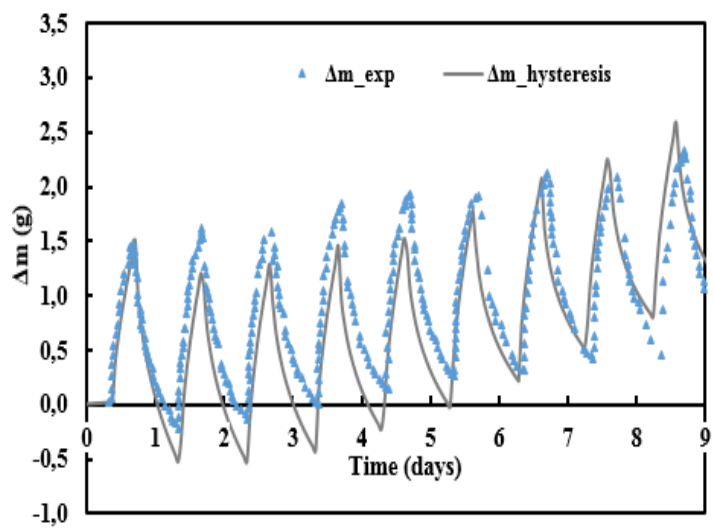

Figure 2: Hysteresis model calibration. 


\section{Application at wall scale}

\section{Quick review of experimental set-up}

A $36 \mathrm{~cm}$ hemp concrete wall $\left(2.7 \times 2.1 \mathrm{~m}^{2}\right)$ is studied. It is subjected for 87 days to temperature and relative humidity conditions on both inner and outer sides using a bi-climatic chamber (Lelievre et al, 2014). Specific probes record temperatures and relative humidities at three locations within the wall: $\mathrm{x}=5 \mathrm{~cm}, \mathrm{x}=18 \mathrm{~cm}$ and $\mathrm{x}$ $=29 \mathrm{~cm}$ as seen in Figure 2. Sensors uncertainties on temperature and relative humidity are given by the supplier and evaluated at $0.5{ }^{\circ} \mathrm{C}$ and $2 \%$, respectively. Indoor conditions are set to $23{ }^{\circ} \mathrm{C}$ and $50 \%$ relative humidity during the experiment. Outdoor conditions are presented in Table 2. Initial temperature and relative humidity (at day 0) are supposed to be $23^{\circ} \mathrm{C}$ and $50 \%$ respectively from inner and outer sides.

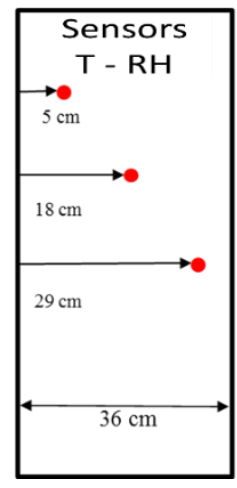

Figure 3: wall and sensors scheme.

Table 2: Experimental outdoor conditions

\begin{tabular}{|c|c|c|}
\hline Sequence & $\begin{array}{c}\text { Temperature } \\
\left({ }^{\circ} \mathbf{C}\right)\end{array}$ & $\begin{array}{c}\text { Relative } \\
\text { humidity }(\boldsymbol{\%})\end{array}$ \\
\hline 1: $] 0-20]$ days & 32 & 50 \\
\hline 2: $[20-55]$ days & 32 & 30 \\
\hline 3: $[55-70]$ days & 17 & 85 \\
\hline 4: $[70-87]$ days & 23 & 50 \\
\hline
\end{tabular}

\section{Models description}

In order to evaluate hysteresis impact at both wall and room scales, two models are established. The first one is a standard heat and moisture transfer model based on Philip and De Vries (1957) transport theory and using mean hemp concrete sorption curve. The second one involves hysteresis modelling and therefore material's hydric behaviour is represented by its scanning curves and not by average sorption isotherm. Models are implemented in SPARK simulation tool allowing to solve differential equations using finite difference method (Sowell and Haves, 2001). Table 3 summarizes models characteristics.
Table 3: Models description.

\begin{tabular}{|c|cl|}
\hline Models & & \multicolumn{1}{c|}{ Description } \\
\hline Mod_1 & - & Standard HAM model \\
& - & Average sorption curve \\
& - & Initialisation at $23^{\circ} \mathrm{C}$ and $50 \%$ R.H \\
\hline Mod_2 & - & Hysteresis taking into account \\
& - & $\begin{array}{l}\text { Primary and scanning curves } \\
\text { implementation }\end{array}$ \\
& - & $\begin{array}{l}\text { Initialization at } 23^{\circ} \mathrm{C} \text { and } 50 \% \text { R.H } \\
\text { from adsorption curve }\end{array}$ \\
\hline
\end{tabular}

\section{Results and discussion}

Figures below show a comparison between experimental measurements of temperature and relative humidity and numerical predictions delivered by SPARK at three specified locations.

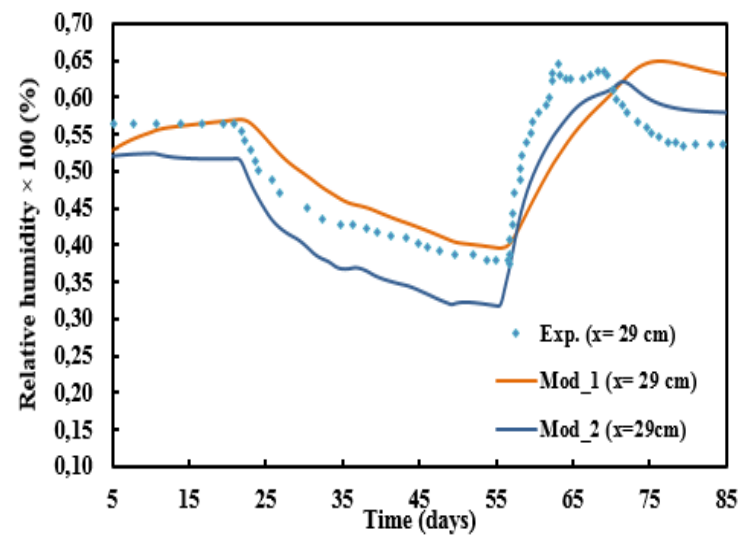

Figure 4: Relative humidity comparison at $x=29 \mathrm{~cm}$.

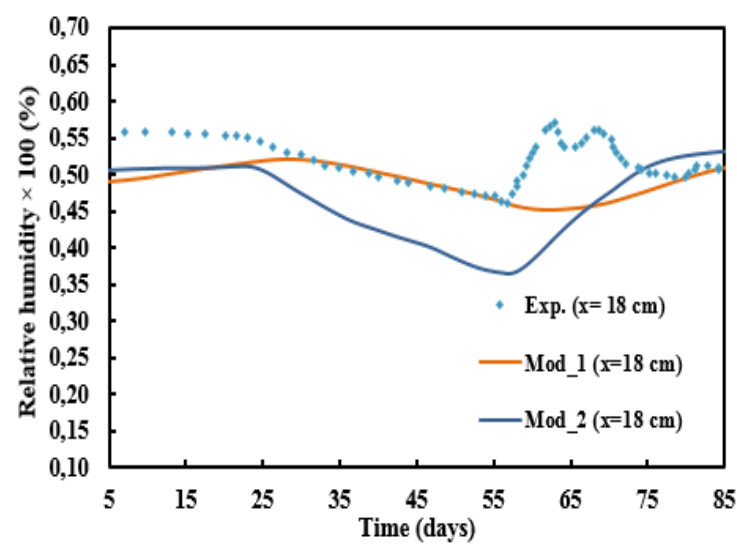

Figure 5: Relative humidity comparison at $x=18 \mathrm{~cm}$. 


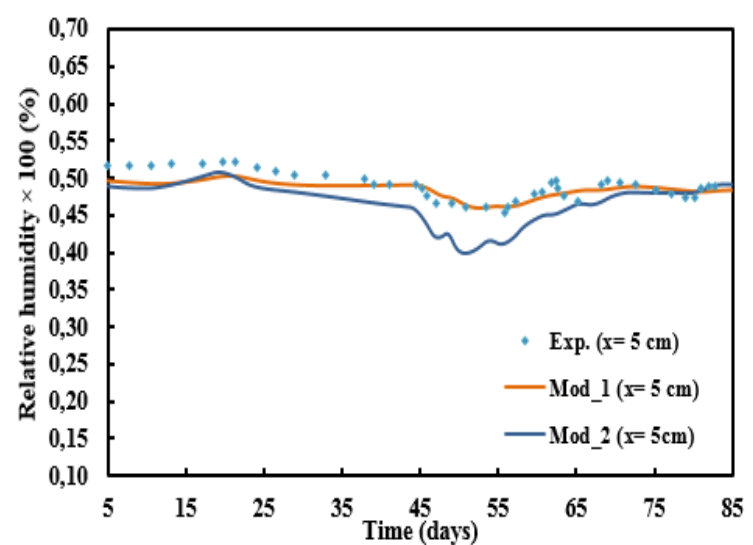

Figure 6: Relative humidity comparison at $x=5 \mathrm{~cm}$.

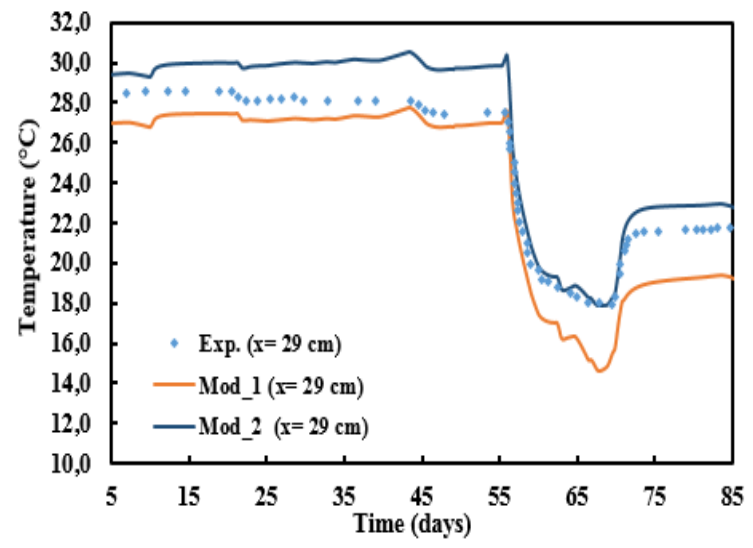

Figure 7: Temperature comparison at $x=29 \mathrm{~cm}$.

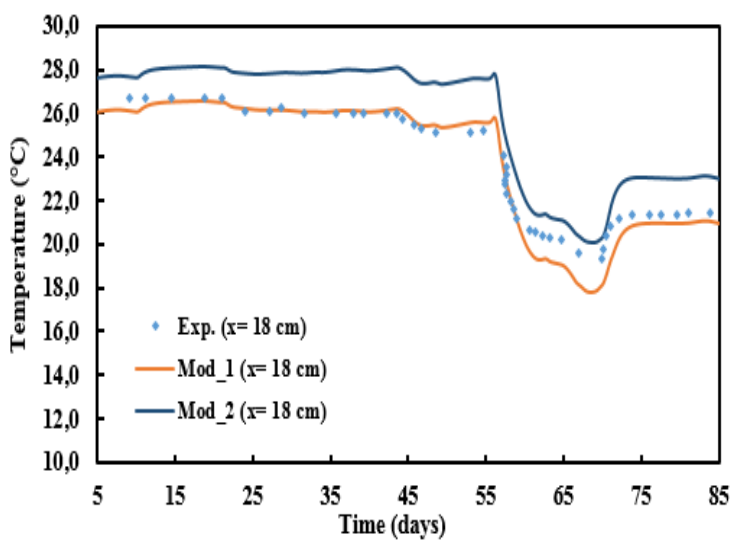

Figure 8: Temperature comparison at $x=18 \mathrm{~cm}$.

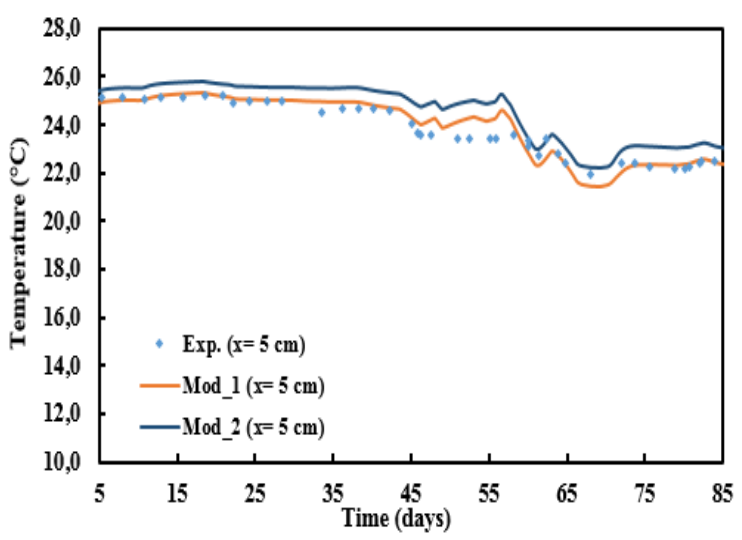

Figure 9: Temperature comparison at $x=5 \mathrm{~cm}$.
At $\mathrm{x}=29 \mathrm{~cm}$, temperature profiles (Figure 7) are acceptable for the 2 models up to the 55th day with an underestimation (between 0,5 and $2{ }^{\circ} \mathrm{C}$ ) for Mod_1 and an overestimation (from 1,5 to $2{ }^{\circ} \mathrm{C}$ ) for Mod_2. Beyond that, temperature prediction is advantageous for Mod_2 and deteriorated for Mod_1 with differences reaching 4 ${ }^{\circ} \mathrm{C}$ with experimental data. Figure 7 shows that when temperature is overestimated over the first 55 days, relative humidity is underestimated and vice versa (Figure 4). After that, Mod_2 represents well relative humidity dynamic variations while Mod_1 show reduced arising slopes and delayed relative humidity peaks.

In the middle of the wall (Figure 5), prediction of relative humidity dynamic evolution is acceptable until day 55 especially for Mod_1. Beyond this, profile obtained does not fit well with experimental measurements for the é models. Same results are obtained by Lelievre et al. (2014) using COMSOL simulation tool. Regarding temperature profiles (Figure 8), they present good agreement with experimental values for Mod_1 during the first 55 days, while they are overestimated by $2{ }^{\circ} \mathrm{C}$ for Mod_2. In the last twenty days, results remain advantageous for Mod_1 (maximum deviations is about $\left.1.5^{\circ} \mathrm{C}\right)$.

Figure 9 shows that the 2 models are reliable for temperature variations prediction from the wall inner side since deviations from experimental data do not exceed 1 ${ }^{\circ} \mathrm{C}$ at $\mathrm{x}=5 \mathrm{~cm}$. Figure 6 gives advantage to Mod_1 with maximum differences of about $2 \%$ with experimental values. However, Mod_2 succeeds in predicting evolution dynamics.

In summary, and considering sensors uncertainties $\left(0.5^{\circ} \mathrm{C}\right.$ and $2{ }^{\circ} \mathrm{C}$ ), Mod_1 not taking hysteresis into account, gives good results during the first 55 days when wall history is not well controlled. Later on, when adsorption and desorption cycles are applied, taking hysteresis into consideration (Mod_2) improves relative humidity variations within the wall. Concerning temperature variations, it seems that hysteresis (Mod_2) brings improvements to thermal behaviour prediction when the wall is subjected to variable conditions (beyond 55 days).

\section{Application at room scale}

\section{Room presentation}

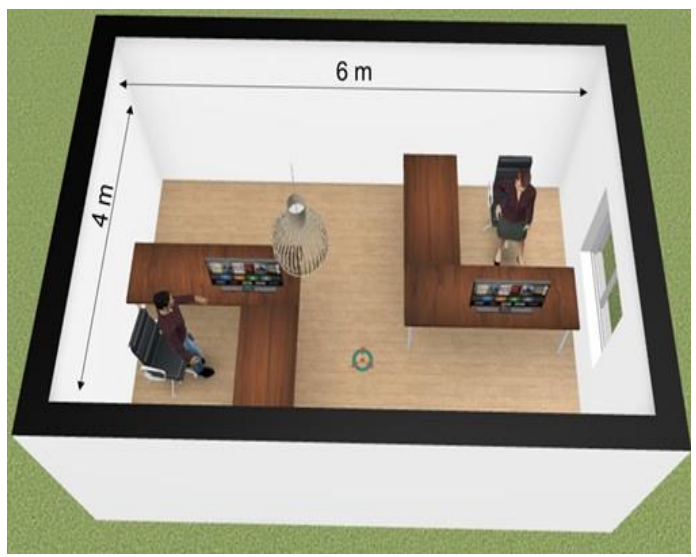

Figure 10 : Office studied scheme (Moussa et al., 2018). 
In this section, the room studied is an office of $6 \times 4 \times 3$ $\mathrm{m}^{3}$ (Figure 10). Its south façade consists of a single hemp concrete layer of $36 \mathrm{~cm}$ and contains a double glazed window (Moussa et al., 2018). Same hemp concrete properties of previous section are used. Remaining vertical walls are internal partitions considered adiabatic with a gypsum coating on both sides. Heat sources in the room are due to two $130 \mathrm{~W}$ computers and a $90 \mathrm{~W}$ light source. The office is supposed to be occupied by two persons for 6 days per week (Monday to Saturday from $8 \mathrm{~h}$ to $13 \mathrm{~h}$ and $14 \mathrm{~h}$ to $18 \mathrm{~h}$ ). Heating and cooling demands are calculated using a proportional integrator PI controller. Modelling nodal approach is considered and variable air flowrate ventilation is applied according to internal relative humidity (Figure 11). Climate outdoor conditions used as models entries represent the weather of Nancy city located in Grand-Est region, north of France.

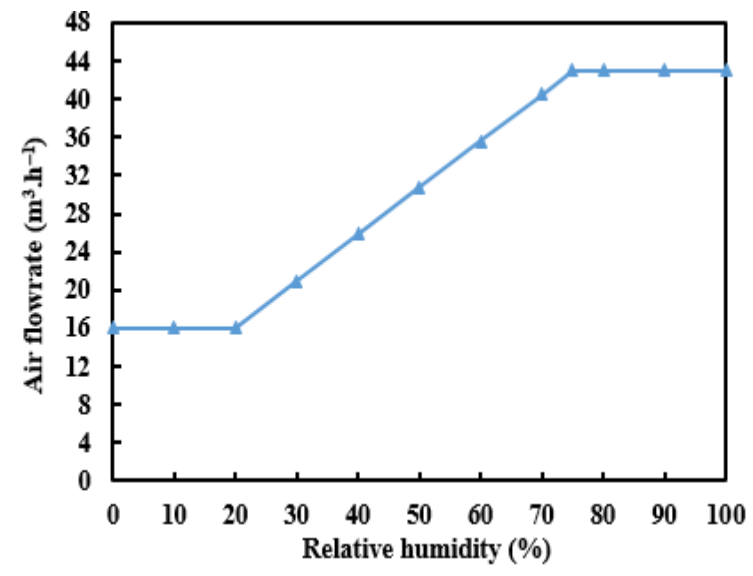

Figure 11: Variable ventilation flowrate.

Room indoor temperature and relative humidity as well as energy consumption for heating and cooling are investigated for two cases: with and without considering hemp concrete hysteresis in the modelling.

\section{Results and discussion}

Two periods of 10 days each are selected and compared during summer and winter periods in figures below. In addition, Table 4 presents global energy demands for each model.

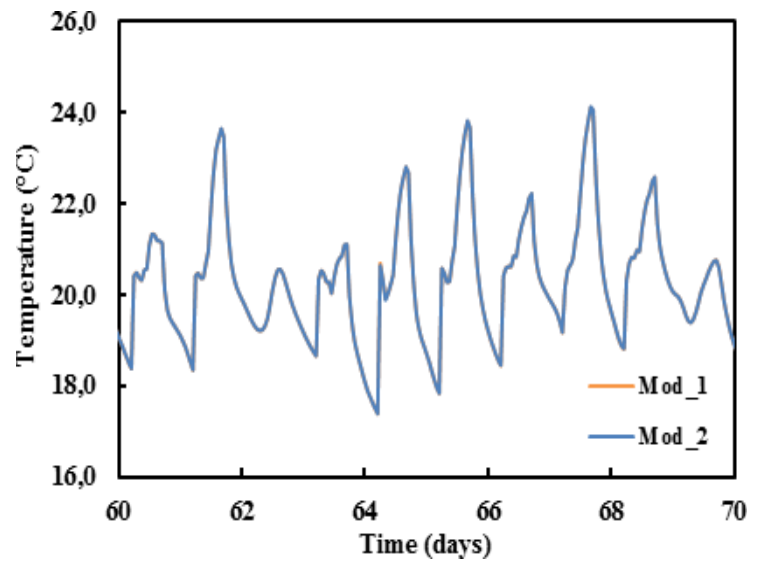

Figure 12: Temperature comparison in winter season.

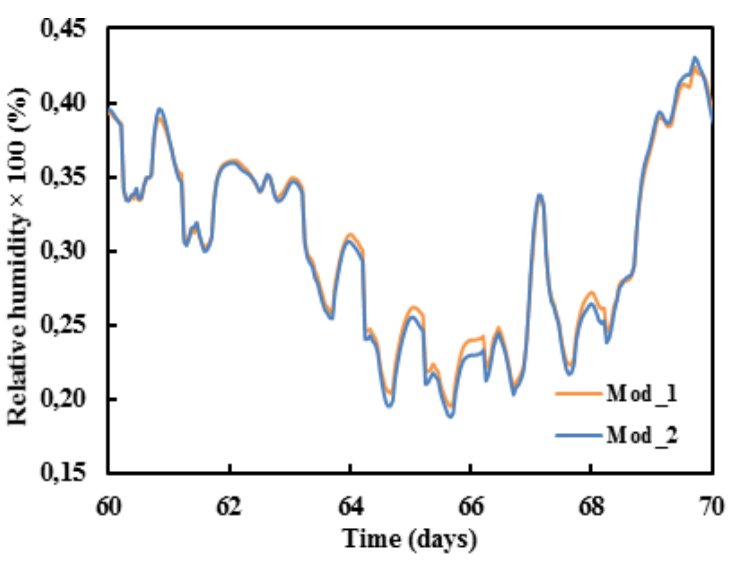

Figure 13: Relative humidity comparison in winter season.

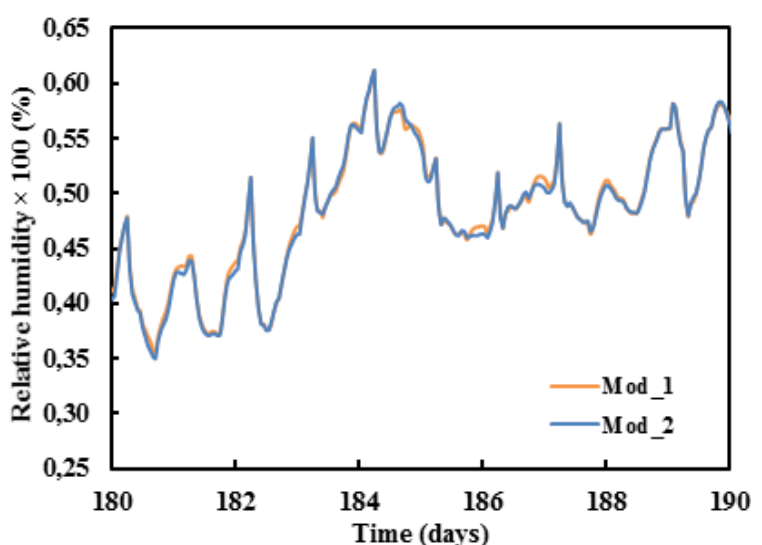

Figure 14: Temperature comparison in summer season.

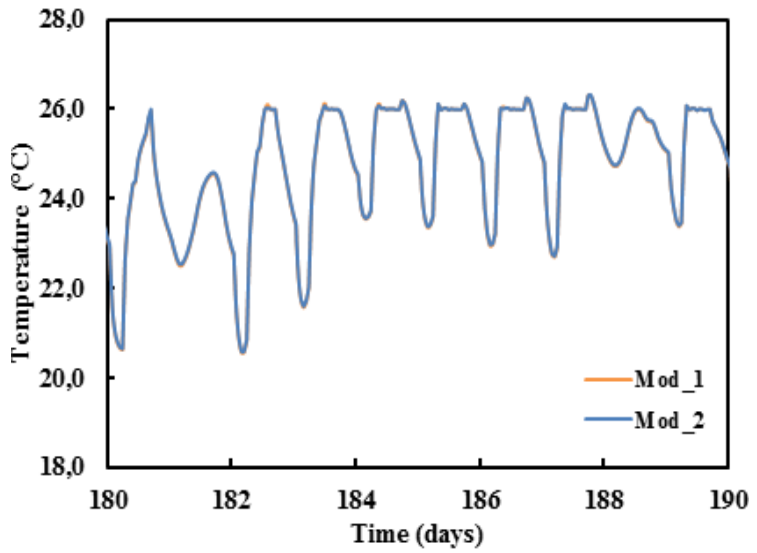

Figure 15: Relative humidity comparison in summer season

Table 4: Comparison of annual energy demands.

\begin{tabular}{|c|c|c|c|}
\hline Models & $\begin{array}{c}\text { Heating } \\
\text { (Kwh) }\end{array}$ & $\begin{array}{c}\text { Cooling } \\
\text { (Kwh) }\end{array}$ & $\begin{array}{c}\text { Total } \\
\text { (Kwh) }\end{array}$ \\
\hline Mod_1 & 600.9 & 150.9 & 751.8 \\
\hline Mod_2 & 598.5 & 154.1 & 752.6 \\
\hline
\end{tabular}

Indoor air temperature profiles are almost identical for the two models, whether in winter (Figure 12) or in summer (Figure 14), due to imposed regulation effect. Relative humidities are also very close with maximum differences of around $3 \%$ in winter (Figure 13) and 1\% in summer (Figure 15). Similarly, regarding energy consumption for 
heating and cooling (Table 4), it must be stated that negligible differences are observed between Mod_1 and Mod_2. As a result, it can be noticed that hysteresis has low impact on indoor conditions prediction at room scale. Hysteresis limited impact on indoor conditions is in agreement with the results given by Carmeliet et al. (2005) who worked on a wooden room: according to them, main reason lies in minor differences in hydric capacities (or in other words sorption curves slopes) between adsorption, desorption and intermediate scanning curves.

\section{Conclusion}

In this work, a numerical study of hemp concrete at wall and room scales is conducted. Hysteresis impact on hygrothermal behavior prediction is studied. To this end, two numerical models are created, implemented and tested under various conditions. Results show that considering hysteresis at wall scale permits to take into account material age and to improve the prediction of its dynamic evolution hygrothermal behavior. Meanwhile, it should be pointed out that standard model with average sorption curve provides acceptable performance especially from wall inner side.

Moreover, a hemp concrete office is studied with a particular interest to internal conditions of temperature and relative humidity and to energy consumption for heating and cooling. Results show that considering hysteresis and in hemp concrete slightly affects indoor relative temperatures and humidities, as well as heating and cooling demands. Standard model, which is easy to implement and fast in computation, could be consider reliable in this field.

\section{Conclusion}

This work was carried out in the scope of a $\mathrm{PhD}$ thesis project funded by the European Regional Development Fund (ERDF).

\section{References}

Amziane, S. and Arnaud, L. (2013) Bio-aggregate-based building materials: applications to hemp concretes. Wiley-ISTE. Available at: https://www.wiley.com/enus/Bio+aggregate+based+Building+Materials\%3A+Appl ications+to+Hemp+Concretes-p-9781848214040

Van Belleghem, M. et al. (2010) 'Sensitivity analysis of CFD coupled non-isothermal heat and moisture modelling', Building and Environment, 45(11), pp. 24852496. doi: 10.1016/j.buildenv.2010.05.011.

Carmeliet, J., De Wit, M. H. D. and Janssen, H. (2005) 'Hysteresis and moisture buffering of wood', in Proceedings of the Nordic Symposium on Building Physics. Reykjavik, Iceland, pp. 55-62.

Colinart, T. et al. (2013) 'Experimental Study on the Hygrothermal Behavior of a Coated Sprayed Hemp Concrete Wall', Buildings, 3, pp. 79-99. doi: 10.3390/buildings3010079.

Costantine, G. et al. (2018) 'Experimental and numerical investigations of thermal performance of a Hemp Lime external building insulation', Building and Environment.
Pergamon, 131, pp. 140-153. doi: 10.1016/J.BUILDENV.2017.12.037.

D'Alessandro, F., Asdrubali, F. and Baldinelli, G. (2014) 'Multi-parametric characterization of a sustainable lightweight concrete containing polymers derived from electric wires', Construction and Building Materials, 68, pp. 277-284. doi: 10.1016/j.conbuildmat.2014.06.075.

Fabbri, A. and McGregor, F. (2017) 'Impact of the determination of the sorption-desorption curves on the prediction of the hemp concrete hygrothermal behaviour', Construction and Building Materials, 157, pp. 108-116. doi: 10.1016/j.conbuildmat.2017.09.077.

Hansen, K. K. (1986) Sorption Isotherms. A Catalogue. Copenhagen.

Kool, J. B. and Parker, J. C. (1987) 'Development and evaluation of closed-form expressions for hysteretic soil hydraulic properties', Water Resources Research, 23(1), pp. 105-114. doi: 10.1029/WR023i001p00105.

Lelievre, D. (2015) Simulation numérique des transferts de chaleur et d'humidité dans une paroi multicouche de bâtiment en matériaux biosourcés. Université BretagneSud.

Lelievre, D., Colinart, T. and Glouannec, P. (2014) 'Hygrothermal behavior of bio-based building materials including hysteresis effects: Experimental and numerical analyses', Energy and Buildings, 84, pp. 617-627. doi: 10.1016/j.enbuild.2014.09.013.

Leon, C. A. and Uantachrome, L. (1998) 'New perspectives in mercury porosimetry', Advances in Colloid and Interface Science, pp. 341-372. Available at: https://ac.els-cdn.com

Maalouf, C. et al. (2014) 'Study of hygrothermal behaviour of a hemp concrete building envelope under summer conditions in France', Energy and Buildings, 77, pp. 48-57. doi: 10.1016/j.enbuild.2014.03.040.

Moujalled, B. et al. (2018) 'Experimental and numerical evaluation of the hygrothermal performance of a hemp lime concrete building: A long term case study', Building and Environment. Pergamon, 136, pp. 11-27. doi: 10.1016/J.BUILDENV.2018.03.025.

Moussa, T. et al. (2018) 'Bio-based and recycled-waste materials in buildings: A study of energy performance of hemp-lime concrete and recycled-polyethylene terephthalate façades for office facilities in France and Italy', Science and Technology for the Built Environment. Taylor \& Francis, 24(5), pp. 492-501. doi: 10.1080/23744731.2018.1438664.

Mualem, Y. (1974) 'A conceptual model of hysteresis', Water Resources Research, 10(3), pp. 514-520. doi: 10.1029/WR010i003p00514.

Naono, H. and Hakuman, M. (1993) 'Analysis of Porous Texture by Means of Water Vapor Adsorption Isotherm with Particular Attention to Lower Limit of Hysteresis Loop', Journal of Colloid and Interface Science. Academic Press, 158(1), pp. 19-26. doi: 10.1006/JCIS.1993.1223.

Pedersen, C. R. (1990) 'Transient calculation on moisture 
migration using a simplified description of hysteresis in the sorption isotherms', Proceedings of the 2nd symposion on Building Physics in the Nordic Countries, (Technical University of Norway, Trondheim, Norway.). Philip, J. R. and De Vries, D. A. (1957) 'Moisture movement in porous materials under temperature gradients', Transactions, American Geophysical Union, 38(2), p. 222. doi: 10.1029/TR038i002p00222.

Rode, C. ; and Woloszyn, M. (2007) 'Proceedings-Thermal Performance of the Exterior Envelopes of Whole Buildings X', in Proceedings - Thermal Performance of the Exterior Envelopes of Whole Buildings: Buildings $X$. American Society of Heating, Refrigerating and AirConditioning Engineers, pp. 1-15.

Rode Pedersen, C. (2005) Moisture buffering of Building Materials. Denmark.

Simonson, C. J., Salonvaara, M. and Ojanen, T. (2002) 'The effect of structures on indoor humidity--possibility to improve comfort and perceived air quality.', Indoor air, 12(4), pp. 243-51.

Sowell, E. F. and Haves, P. (2001) 'Efficient solution strategies for building energy system simulation', Building Physics, 33, pp. 309-317.

Viitanen, H. et al. (2010) 'Moisture and Bio-deterioration Risk of Building Materials and Structures', Journal of BUILDING PHYSICS, 33(3). doi: 10.1177/1744259109343511.

Wolkoff, P. (2018) 'Indoor air humidity, air quality, and health - An overview', International Journal of Hygiene and Environmental Health, 221(3), pp. 376-390. doi: 10.1016/j.ijheh.2018.01.015.

Y. Ait Ouméziane (2013) Evaluation des performances hygrothermiques d'une paroi par simulation numérique: application aux parois en béton de chanvre. INSA de Rennes. 